\title{
An integrated platform for managing information in smart cities
}

\author{
Justas Streimikis ${ }^{1,2 *}$,Evgeniy Kislitsyn ${ }^{3}$, Nadezhda Surnina $^{3}$, and Viktor Gorodnichev ${ }^{3}$ \\ ${ }^{1}$ Institute of Economics and Rural Development, Lithuanian Centre for Social Sciences, A. Vivulskio \\ g. 4A-13, LT-03220 Vilnius, Lithuania \\ ${ }^{2}$ University of Economics and Human Science in Warsaw, Faculty of Management and Finances, \\ Okopowa 59, 01-043Warsaw, Poland \\ ${ }^{3}$ Ural State University of Economics, 62 8-Marta Str., Ekaterinburg, 620144, Russian Federation
}

\begin{abstract}
This article focuses on defining the integrated platform for managing information in smart cities. We look into the smart city platforms that are increasingly used in today's cities all around the world. Smart city platforms can be deployed on private, public or hybrid clouds, remote servers or onsite. By definition, a smart city platform integrates many different functional areas of the smart city in a single environment. The Smart city platform offers integrated functionality to coordinate intelligent city data, applications, solutions and services at one or more operational levels between multiple stakeholders with integrated functionality. By monitoring and analysing the use of urban assets, the government can distribute them to improve operational efficiency. The platform provides middleware and operational functionality across multiple software and hardware, integrates multiple communication protocols, and provides latent and free solutions for smart cities. Managing the huge amounts of data generated by IoT-based sensors and systems is a main challenge facing end users and providers. We show that smart city platforms serve to standardize data and information across many silo systems. It is demonstrated that they provide a common mechanism for visualizing and managing data to optimize the entire urban operation.
\end{abstract}

Keywords: smart cities, information management, integrated platforms.

\section{Introduction}

More and more end users, owners and operators are beginning to see the value of a unified smart city platforms that are building unique bridges between smart cities and smart homes [1]. This is where communities and citizens can learn how to benefit from the ongoing digital transformation. While many small municipalities have installed smart meters to measure electricity use and a handful of large metropolitan areas have adopted a wide range of systems and technologies for key functions, the world of smart cities remains an enormous challenge that needs to be addressed and understood $[2,3]$.

\footnotetext{
*Corresponding author: justas.streimikis@gmail.com
} 
The Internet of Things (IoT) has played a key role in shaping the digital landscape of smart cities, with connected sensors and devices creating millions of control ends points that generate real-time data about operations and automate human actions [4]. The architecture of the industrial Internet of Things for smart city platforms lies at the corporate level. Smart city platforms enable users to integrate different sensors, machines, people, vehicles and other devices with a variety of applications and usage conditions. They perform many functions including analytics, remote asset monitoring, performance management, decision support and component presentation. Information is integrated as far as possible from existing vendors of urban infrastructure, citizen applications, open data and external databases and can be done in different ways [5]. Smart city platform providers can specialize in one or more smart city applications, such as intelligent lighting and traffic management systems, or software platforms that integrate data from multiple smart city applications areas [6].

Many end users attempt to integrate information into a unified whole to give a holistic view of the overall performance and state of the city and its diverse functions. The move towards an integrated approach to city management, supported by ICT-oriented services, can be observed. The information is associated with urban infrastructures, citizens and applications, other technologies used to obtain information, external databases and other data repositories and the connections used to transmit the received information [7]. The purpose of this paper is to propose integration of middleware to support the management of smart cities in a dynamic, transparent and scalable way. The idea of the smart city concept encompasses a large number of fields and technologies that fit the concept but are not consolidated. The clear trend is a shift from silo approaches to integrated approaches and organisational models for municipalities. An intelligent city uses the information and communication technology (ICT) to improve the quality of life of its citizens, increase the efficiency of urban operations and services and ensure that the needs of current and future generations are fulfilled economically, socially and environmentally [8].

The existence of the main approaches for collecting static statistical sources of dynamic data from intelligent devices is done using sensors, tags, GPS, GIS and smartphones. This approach is to collect data and then identified one or more urban problems, such as in London, which focuses on improving the delivery of public transport in less central areas of the city [9]. The limitations of this approach are, on the one hand, an exaggerated silo vision focusing on a single service in the same area and, on the other, the advantage of optimising certain services, which risks excluding the possibility of integrating large amounts of data from other areas with other services. Private companies, in collaboration with universities and a private general system enable users to use and store read and write access to data to be used by developers offering services to cities [10]. The tools they offer are crucial: the operating system of the Smart city platform, for example, provides a range of visual tools for developing applications and reducing costs and effort.

\section{Sustainable cities with a minimized $\mathrm{CO} 2$ footprint}

In order to reduce the environmental impact of transport in conurbations, sustainable transport has three agreed pillars and should be used to create healthy and productive urban centres. The Carbon Trust notes that there are three main ways cities can innovate to make transportation more sustainable [11].

Since large parts of a city's carbon footprint are generated by cars, this concept should be seen as an integral part of the design of sustainable cities. Cities and urban areas can reduce the greenhouse gases and local air pollution by investing in existing technologies. Safe, equitable and energy-efficient urban transport can contribute to achieving several health and sustainability objectives [12]. The shift to urban planning and infrastructure investment in public transport networks to prioritise high-speed bus, light rail and private vehicles can 
reduce the long-term development of air pollution and climate emissions caused by private transport, improve health and fairness and provide better mobility for those who do not have a car. Cities have a unique opportunity to reduce emissions and air pollution through leveraging synergies between different sectors of the urban energy system [13]. Investments in energy-efficient heating and cooling of buildings and electrified transport will allow sectoral coupling and close half of the gap in reducing urban greenhouse gases needed to meet the $1,5^{\circ} \mathrm{C}$ target in Paris. Cities can act as ambitious and inspiring pioneers, showcasing new and efficient technologies to create attractive and futuristic places to live and work. Cities play an important role in combating climate change, as their risk of climate disasters increases as they grow. Billions of city dwellers live in coastal areas, increasing their vulnerability to storm surges and sea rise $[14,15]$. The key to success lies in connectivity and integration, in exploiting cross-sectoral synergies, in combining electricity, transport, heating, cooling, water and wastewater to manage energy demand and supply intelligently and efficiently. Of the 136 largest coastal cities with more than 100 million inhabitants, 20\% of their population and $\$ 4.7$ trillion in assets are exposed to coastal flooding. More than $90 \%$ of urban expansion in developing countries takes place in vulnerable are as built on informal and unplanned settlements. Even though, today, more than half of the world's population lives in cities. Cities occupy 3 percent of the Earth's surface and account for 60 to 80 percent of the energy consumption and 70 percent of the carbon emissions [16].

In many cities and towns, passenger cars are the biggest emitters, and millions of vehicles are on the road every day. In order to reduce greenhouse gas emissions, people should use cleaner means of transport such as public transport, cycling and walking [17]. Modern transport depends on petroleum for passenger cars and light commercial vehicles. Diesel vehicles are also a serious source of fine particulate matter emissions, including soot, a climate pollutant, and short-lived climate pollutants, a component of particulate matter pollution.

Another factor in greenhouse gas emissions is the production and operation of the car. Electric vehicles emit more emissions in vehicle construction than internal combustion engines, which affects the duration of three years. The app assesses cars based on their mileage, fuel type, emissions from the car's production and whether they are electric vehicles or generate electricity to run the car. Let us look at some ways to reduce your carbon footprint now that we have a more detailed understanding of carbon emissions and climate change. Petrol cars and taxis tend to emit a lot of carbon dioxide per kilometre driven. Whether you are flying to work or pleasure, air travel is responsible for a large part of it. Public transport, such as trains, buses and coaches, which carry many people, is a more sustainable form of travel. A lot of carbon dioxide per kilometre driven is spilled by the few people who make it there in an energy-intensive way. The city plans to eliminate greenhouse gases by 2040 by encouraging residents to walk and use public transportation, especially its new hydrogenpowered buses [18]. The city produces the lowest greenhouse gas emissions of any major city in North America, and this initiative continues with environmental improvements. Some researchers estimates that in a few years the global smart city market will be worth than it is now and the concept is also becoming more important in the industries, the political and community discourse, and urban development [19].

\section{Urban infrastructure with resources consumption}

In general terms, the energy consumption examines not only food production and energy use, but the whole food system, including the treatment and treatment of waste. The potential for the impacts on energy demand and production is significant [20]. Changes in energy consumption relative to the status quo in the food-energy-water nexus should be studied to 
validate the ecological case and avoid unintended shifts that affect one resource system over another.

Urban agriculture has the potential to influence energy-related components of food, energy and water systems across urban boundaries. It is worth noting that the depth of groundwater sources, pumping requirements and treatment of surface and groundwater farms influences energy demand and bring these figures with those of water utilities [21]. As an increasing percentage of the global population and economic activity is concentrated in urban areas, cities are increasingly relevant if not central to the discussion on sustainable development. As cities concentrate people and resources and this contributes to their sustainability it is clear that cities are unsustainable in non-urban areas without the support of ecosystems and services, including ecosystem products such as raw materials and food. Given that materials and energy are used to support urban areas from the great distances around the world, it is crucial for cities to understand how activities and consumption within their borders affect places and people within them [22]. Billions of city dwellers live in coastal areas, increasing their vulnerability to storm surges and sea rise. More than $90 \%$ of urban expansion in developing countries takes place in vulnerable areas built on informal and unplanned settlements. The 136 largest coastal cities have more than 100 million inhabitants, and $20 \%$ of their population and $\$ 4.7$ trillion in assets are exposed to coastal flooding [23].

Sustainable smart cities initiatives help overcome the constraints of traditional urban development, which tends to manage urban infrastructure systems in silos. They take advantage of the ubiquitous nature of data and services that digital technologies such as cloud computing, IoT and open data offer. This contributes to networking different stakeholders in the city, improving citizen participation, offering new or existing services and providing a context-conscious view of urban events [24]. It is also a good way to tackles the ubiquitous corruption issue that plagues many cities and countries all around the world and disrupts the functioning of the small and large business [25].

In other words, it is crucial to identify the potential of energy-water values for water and wastewater utilities and the electricity utilities that serve the large cities on the planet. The types of concepts that define and enrich the understanding of energy consumption in the water and wastewater sector and vice versa and the potential utilities that these systems provide, can help bridge the knowledge gap between water and energy systems and promote maturity of this area. For example, the energy value of the water and wastewater sectors is at a high level. It is estimated that pumping, treating and distributing water required 34.65 billion $\mathrm{kWh}$ of energy in 2015 in the United States and special processes such as UV disinfection require $25.55 \mathrm{kWh}$ per million treated gallons [26]. Despite this value, there is insufficient research at national level on the interactions between energy and water supply in cities and energy consumption depending on local water quality regulations, the technologies used, the population and the geographical layout of the system. Water indicators such as water consumption rates, patterns, intensities and footprints as well as water consumption for energy-related processes (energy indicators such as direct and indirect energy consumption, intensities and carbon footprints are energy indicators. Food indicators such as crop yields, food consumption patterns, water and energy contributions to food development, distribution and consumption as well as waste management and recycling include. The results can be seen through the bio-waste, municipal waste, agricultural waste and other organic waste.

\section{Software infrastructure for smart cities planning}

A range of services that includes strategy, organization, municipal informatics, business systems, architecture and infrastructure, as well as advice on what to do to provide intelligent services constitutes a key to the pandemic planning and emergency solutions that enable public authorities and municipalities to carry out thorough preparedness and response 
planning for major health crises [27, 28]. This is how any city can develop and implement a master plan that embodies its unique vision and priorities across the various city planning departments and leverages processes such as capital improvement, budgeting, data management and analysis to create a culture of innovation, efficiency and sustainability. Smart and Green urban planning services enable cities to adopt energy and technology solutions to minimise environmental impacts and save money, and support the integration of smart technologies to create resilient urban infrastructure [29]. The cities can assess the initial conditions, energy and climate impacts of various programs and strategies, as well as innovative, smart new technologies from sensors and micro-grids to smart electric vehicles. As independent experts on built environment, we understand how technology can be used to help cities thrive. They see smart cities as one of the tools for urban development that puts people first [30].

Smart cities use data and technology to improve efficiency, sustainability, economic development and quality of life of people living and working in cities. Policymakers, executives, city governments, developers, and industry to define how much they can invest and how much value they can derive from being intelligent. Smart cities combine ICT infrastructure, physical infrastructure, social infrastructure and economic infrastructure, using their collective intelligence to make themselves sustainable, efficient, functional, resilient, liveable and equitable [31].

Since the 1990s, city officials around the world have been investing in modernizing the information and communication technology to create intelligent interactions between machines with the aim of achieving cost savings, enhancing efficiency, governance and transparency for city officials and the community. Partly influenced by the Internet of Things and big data trends, typical smart city projects are crowd control, police management, parking, street lighting, traffic planning, mapping, water and energy management and litter collection. In the recent years, countries and cities have been equipped with common technologies such as back-end systems, computer software interfaces and fixed-line telephones. But many of the world's fastest-growing cities bypass them today and are able to manage with mobile and wireless facilities, giving them greater flexibility in applying the smart city concept [32].

As cities integrate all sorts of ICT forms, including infrastructure platforms, systems, devices, sensors, actuators and networks, the volume of data generated by cities grows and diversifies, providing a rich and heterogeneous flow of information about the urban environment and citizens. Data-driven insights made possible by cloud computing and AI technologies can be used to improve urban operations and citizens' lives by improving the quality, performance and interactivity of urban services and resources and to encourage economic growth. The ability to predict and solve problems before they occur increases resilience and supports more sustainable lifestyles, including reducing consumption and cost of amenities such as water, gas and electricity and optimizing the efficiency of urban operations and services [33].

Under the unified auspices of smart city hubs, this type of data-driven approach can be implemented in other ways. Complexity, combined with different data silos, multi-vendor system architectures, and the number of citizens it supports, can make IT development seem overwhelming. We have developed an integrated multi-infrastructure model that takes into account the relationship between land, buildings, energy, water, food and mobility systems. Nature-based solutions with next-generation cyber-physics can become the solution. Smart cities can also be urban areas where different electronic methods and sensors are used to collect data.

The model of a data-driven smart and sustainable city comprises nine different dimensions and functions. As for research centres and innovation laboratories, they are associated with research and innovation in order to develop and disseminate functions of 
urban intelligence. The knowledge gained from the data will be used to manage assets, resources and services and will be used in exchange for the data to improve the operation of the urban area which uses various electronic methods and sensors to collect data.

\section{Conclusions}

Overall, it becomes apparent that reducing one's carbon footprint can help people to live a healthier lifestyle and save money in large urban centres. Whether it has cleaner air, healthier diets or lower energy bills, the benefits of reducing one's carbon footprint mean people are doing their part to combat climate change.

3D city models can be used to simulate fires, floods and explosions. They also aim to simulate and analyse the impact of explosions in urban areas with high precision to help predict the impact on the structural integrity and the soundness of urban infrastructure as well as the safety and preparation of rescue workers. From this perspective, tools were developed for GIS environments, a sequence process for standardizing and parameterizing workflows, resulting in the automatic classification of objects reflected by laser pulses.

Enriched 3D urban models thus provide a powerful hub for integrating information used for computational urban analysis, including in the context of broader developments such as smart cities and digital twins. Advances in the technology of capturing 3D elevation information from lidar and photogrammetry have made it easier for practitioners in various fields to reconstruct 3D city models. These models can include buildings as well as other types of objects such as bridges, roads, trees and water.

The availability of applications for 3D models is increasing, and the areas of urban planning and environmental simulation are listed below. Officials can use scanners to collect data and the resulting models to stay informed and have access to the details needed for projects. Urban analysis and modelling can help urban planners understand residents' needs.

City information modelling is particularly useful for architects and planners of large-scale urban and urban planning projects. With CIM users can create and display 3D city models for any environment where data is available at any time and location and act as an analytical tool for various city components, including open data from sensors, IoT and social media. With this tool, key players will be able to collaborate and work on a range of 3D models. Typical data sources for 3D city models are CAD models of buildings, locations and infrastructure elements. They offer the highest possible level of detail and do not require a 3D model application to integrate or export their geometry as encapsulated objects. The core component of a 3D city model is a kind of digital terrain model (DTM), which is represented, for example, by a metal grid. Urban planning GIS enables spatial analyses and modelling that contribute to a variety of important urban planning tasks. In urban planning, database management includes the storage of environmental data, socio-economic data and land-use maps for planning and planning applications. Building information models represent categories of geospatial data that can be integrated into 3D city models and provide a high detail level for components.

Remote sensing, spatial queries, and analysis of environmental data can help urban planners identify areas with environmental sensitivity. Today's urban platforms are designed to process and connect large urban datasets from different areas. A large number of important urban planning tasks include site selection, land-use analysis, land use and traffic modelling, planning measures and area assessment. The modelling and optimization functionality is not part of the municipal software infrastructure. For transformation scenarios and development, however, it is crucial to optimise the operation of intelligent cities. Integrated urban platforms are an indispensable software infrastructure for smart, sustainable and resilient urban planning, operation and maintenance. Unplanned urban areas are often inadequate because of a lack of complementary services, such as infrastructure for educational buildings, places 
of worship, administrative authorities and suitable road networks. This paper discusses software architecture concepts such as urban platforms and presents a case study on the results of modelling the construction sector, including urban data analysis and visualization. According to a review by the Centre for Advanced Spatial Analysis, the original land usetransport interaction simulations (LUTI) were used in the 1960s and 1970s, but their usefulness was limited by data quality and computing power. With the rise of GIS in the 1990 s, these models became more informative as the amount of data increased. Governments are developing their own tools to make it easier for officials to access, analyse, and interpret urban data. Although planners have used statistical models for decades to estimate the relationship between factors such as population growth and urban density, these models are far from integrated analytical tools and vehicles for public relations and engagement. Online data collection and sensor systems today generate unprecedented amounts of data in the environment that can increase the predictive power of statistical models. With this regard, GIS helps governments and businesses to process and organise planning applications. Many GIS portals are open to the public, which means that citizens have access to data such as package outlines and information on county boundaries, areas and land-use plans. When important information is available, government resources can be spent on processing requests and searching for data that can be used.

\section{References}

1. R. Sánchez-Corcuera, A. Nuñez-Marcos, J. Sesma-Solance, A. Bilbao-Jayo, R. Mulero, U. Zulaika, G. Azkune, A. Almeida, International Journal of Distributed Sensor Networks, 15(6), 1550147719853984 (2019)

2. K. Kuru, D. Ansell, IEEE Access, 8, 18615-18644 (2020)

3. G. Rausser, W. Strielkowski, D. Štreimikienè, Energy \& Environment, 29(1), 131-146 (2018)

4. N. Hossein Motlagh, M. Mohammadrezaei, J. Hunt, B. Zakeri, Internet of Things (IoT) and the energy sector. Energies, 13(2), 494 (2020)

5. C. Zhang, Future Generation Computer Systems, 112, 630-640 (2020)

6. W. Strielkowski, E. Volkova, I. Pushkareva, D. Streimikiene, Energies, 12(7), 1392 (2019

7. H. Kumar, M. Singh, M. Gupta, J. Madaan, Technological Forecasting and Social Change, 153, 119281 (2020)

8. O. Kosenchuk, O. Shumakova, A. Zinich, S. Shelkovnikov, A. Poltarykhin, Journal of Environmental Management \& Tourism, 5(37), 991-1001 (2019)

9. G. Harrison, S. Grant-Muller, F. Hodgson, Transportation Research Part C: Emerging Technologies, 117, 102672 (2020)

10. C. Lai, Y. Jia, Z. Dong, D. Wang, Y. Tao, Q. Lai, L. Lai, Clean Technologies, 2(3), 290310 (2020)

11. Carbon Trust, https://www.carbontrust.com/news-and-events/insights/sustainabletransport-in-cities (2015)

12. V. Asmantaite, R. Dapkus, V. Karadzic, E. Korneeva, S. Ghauri, Transformations in Business and Economics, 20(1), 53-68 (2021)

13. T. Deetjen, J. Conger, B. Leibowicz, M. Webber, Sustainable Cities and Society, 41, 711-727 (2018)

14. C. Camponeschi, Geoforum, 123, 78-88 (2021) 
15. L. Lovins, S. Wallis, A. Wijkman, J. Fullerton, A finer future: Creating an economy in service to life (2018)

16. M. Ahmad, P. Jiang, M. Murshed, K. Shehzad, R. Akram, L. Cui, Z. Khan, Sustainable Cities and Society, 70, 102881 (2021)

17. Y. Li, C. Lv, N. Yang, H. Liu, Z. Liu, Journal of Cleaner Production, 277, 122419 (2020)

18. I. Ivshina, M. Kuyukina, A. Krivoruchko, A. Elkin, S. Makarov, C. Cunningham, J. Philp, Environmental Science: Processes \& Impacts, 17(7), 1201-1219 (2015)

19. F. Klauser, T. Paasche, O. Söderström, Environment and Planning D: Society and Space, 32(5), 869-885 (2014)

20. K. Kibler, D. Reinhart, C. Hawkins, A. Motlagh, J. Wright, Waste Management, 74, 5262 (2018)

21. E. Mohareb, M. Heller, P. Novak, B. Goldstein, X. Fonoll, L. Raskin, Environmental Research Letters, 12(12), 125004 (2017)

22. J. Burger, J. Brown, J. Day, T. Flanagan, E. Roy, BioPhysical Economics and Resource Quality, 4(1), 1-13 (2019)

23. R. Nicholls, J. Lowe, Global environmental change, 14(3), 229-244 (2004)

24. Z. Engin, P. Treleaven, P. The Computer Journal, 62(3), 448-460 (2019)

25. P. Koudelková, W. Strielkowski, D. Hejlová, Danube: Law, Economics and Social Issues Review, 6(1), 25 (2015)

26. W. Sarni, J. Sperling, A Call to Cities: Run Out of Water or Create Resilience and Abundance? (2019)

27. C. Junior, D. Ribeiro, A. Viana, Sustainable Cities and Society, 66, 102671 (2021)

28. C. Kakderi, N. Komninos, A. Panori, E. Oikonomaki, Sustainability, 13(6), 3158 (2021)

29. Y. Wang, H. Ren, L. Dong, H. Park, Y. Zhang, Y. Xu, Technological Forecasting and Social Change, 144, 103-117 (2019)

30. T. Menkhoff, S. Kan, H. Evers, Y. Chay (eds.), Living in Smart Cities: Innovation and Sustainability (2017)

31. V. Vavrecka, A. Zauskova, A. Privara, M. Civelek, K. Gajdka, Transformations in Business and Economics, 20(2), 223-240 (2021)

32. B. Allen, L. Tamindael, S. Bickerton, W. Cho, Government Information Quarterly, 37(1), 101412 (2020)

33. S. Bibri, Energy Informatics, 4(1), 1-37 (2021) 